\title{
Basketball and drugs: Wastewater-based epidemiological estimation of discharged drugs during basketball games in Kentucky
}

\author{
Alexander Montgomery \\ Murray State University, amontgomery9@murraystate.edu \\ Catherine O'Rourke \\ Murray State University, corourke@murraystate.edu \\ Bikram Subedi \\ Murray State University, bsubedi@murraystate.edu
}

Follow this and additional works at: https://digitalcommons.murraystate.edu/faculty

\section{Recommended Citation}

Montgomery, Alexander; O'Rourke, Catherine; and Subedi, Bikram, "Basketball and drugs: Wastewaterbased epidemiological estimation of discharged drugs during basketball games in Kentucky" (2021). Faculty \& Staff Research and Creative Activity. 89.

https://digitalcommons.murraystate.edu/faculty/89

This Journal Article is brought to you for free and open access by Murray State's Digital Commons. It has been accepted for inclusion in Faculty \& Staff Research and Creative Activity by an authorized administrator of Murray State's Digital Commons. For more information, please contact msu.digitalcommons@murraystate.edu. 


\title{
Basketball and drugs: Wastewater-based epidemiological estimation of discharged drugs during basketball games in Kentucky
}

\author{
Alexander B. Montgomery, Catherine E. O'Rourke, Bikram Subedi * \\ Department of Chemistry, Murray State University, Murray, KY, United States
}

\section{H I G H L I G H T S}

- Amphetamine was significantly discharged higher in the high school basketball game.

- Cocaine was significantly discharged higher in the college basketball game.

- Cocaine was found directly discharged down-the-drain during basketball game.

- Methcathinone was the most abundant NPS in both basketball games.

\section{A R T I C L E I N F O}

\section{Article history:}

Received 18 July 2020

Received in revised form 10 August 2020

Accepted 13 August 2020

Available online 15 August 2020

Editor: Damia Barcelo

\section{Keywords:}

Illicit drugs

Psychoactive drugs

College basketball

High school basketball

Wastewater-based epidemiology

\section{G R A P H I C A L A B S T R A C T}

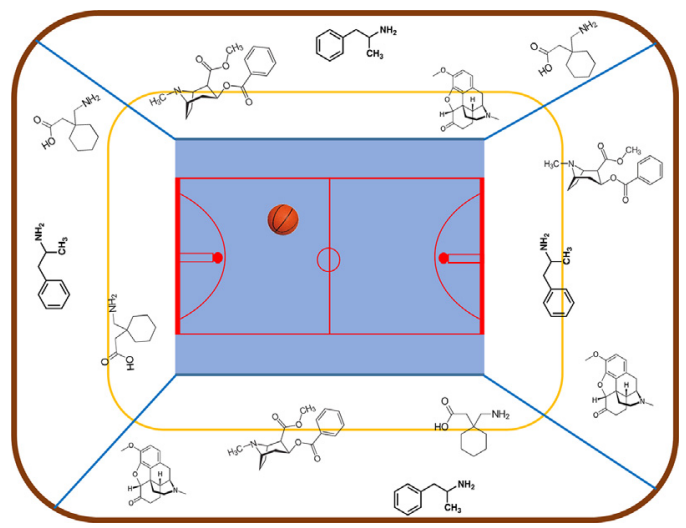

\begin{abstract}
A B S T R A C T
High school sports gather a significantly larger number of fans than college and professional sports in the U.S. Adolescent and adult students in high schools and colleges (aged 12-25) are among the most vulnerable population to substance use. Event planners, risk managers, and emergency medical service personnel can extrapolate the mass loads of drugs in wastewater in this study to evaluate the spectator behavior in relatively larger basketball gatherings. Thirty-three illicit and prescribed psychotic drug residues (out of target 36) and five new psychoactive substances (NPS, out of target 40) were quantified in wastewater, using ultra-performance liquid chromatography and tandem mass spectrometry, discharged during a college and a high school basketball games that were played in the same stadium in Kentucky. The wastewater concentrations of amphetamine, methylphenidate, hydromorphone were significantly higher $(p \leq 0.040)$ during a high school basketball game whereas cocaine, hydrocodone, and gabapentin was significantly higher $(p \leq 0.006)$ in a college basketball game. Higher cocaine to its metabolite ratio suggested that a significant amount of cocaine may have directly discharged down the drain during the college basketball game. Two synthetic cathinones (methcathinone and 4-methyl pentedrone) and three other NPSs (4-ANPP, mCPP, and 4-methylamphetamine) were also quantified in wastewater indicate the prevalence of NPSs in Kentucky. This is the first report of quantified substances of potential abuses at basketball games.
\end{abstract}

(c) 2020 Elsevier B.V. All rights reserved.

\footnotetext{
* Corresponding author at: Department of Chemistry, Murray State University, 1201 Jesse D. Jones Hall, Murray, KY 42071, United States.

E-mail address: bsubedi@murraystate.edu (B. Subedi).
}

\section{Introduction}

The abuse and addiction to illicit and prescribed drugs have increased in recent years and continues to grow globally (UNODC, 2019). Drug poisoning deaths have been the leading cause of injury deaths in the U.S. 
since 2011, above suicide, homicide, firearms, and motor vehicle crashes (DEA, 2018). The number of deaths by overall drug poisoning has quadrupled in the U.S. from 1999 to 2018 (to 67,367) (DEA, 2018; CDC, 2020a), with Kentucky ranked 9th among the states with a drug overdose death rate of 30.9 per 100,000 people in 2018 (CDC, 2020b). The use of methamphetamine in Kentucky has led to a $25 \%$ increase in overdose deaths from 2017 to 2019 (KODCP, 2020).

Adolescents and adults in their twenties are among the highest risk for illicit drug use (Miech et al., 2020). The National Survey on Drug Use and Health reported that the illicit drug users (past year) among people aged 18-25 were almost 2 folds higher (38.7\%) than age groups 12-17 and $\geq 26$ (16.7\% each) in 2018 (SAMHSA, 2019). In the U.S., $62 \%$ of college students are among the age group 18-25 (NCES, 2019). Therefore, there is a potential high use of illicit and prescribed psychoactive substances among high school and college students. In fact, $50 \%$ of high school students used an illicit drug and more than $20 \%$ have abused a prescription drug by the time they are seniors (NIDA, 2014). In a national survey, the prevalence of illicit drug use was 38\% among $\sim 13,700$ twelfth grade students (128 schools) and 15\% among 14,000 eighth grade students (143 schools) (Miech et al., 2020). More interestingly, the annual prevalence of amphetamines among 8-12th graders was second only to marijuana (Miech et al., 2020).

In any mass gatherings, such as sporting events, a developed understanding of audience behavior are critical and can provide useful information to the event planners, risk managers, and emergency medical service personnel for better prediction and minimization of associated public health risk (Hutton et al., 2018). Approximately 50\% of participants of pre-game parties in two college football games were involved in heavy episodic alcohol drinking (Merlo et al., 2011) and 41\% of the spectators of three baseball games were tested alcohol positive (Wolfe et al., 1998). Based on the wastewater analysis, the elevated consumption of illicit drugs such as cannabis, cocaine, methamphetamine, and 3,4-methylenedioxymethamphetamine (MDMA) was reported during the Christmas and New Year's Eve period in Australia (Lai et al., 2013), New Year's Eve, Christmas, and Easter in Belgium (van Nuijs et al., 2011), and Independence Day and the solar eclipse in the U.S. (Foppe et al., 2018). Gul et al. (2016) reported a spiked level of amphetamine and cocaine in Mississippi football game and Gerrity et al. (2011) reported a spiked level of cocaine in municipal wastewater during the Super Bowl football game in the U.S. The mass loading of cocaine was increased up to $718 \mathrm{~g} /$ day in the Super Bowl football game and sevenfold increase during Mississippi football games. However, both of these studies considered analyzing the raw wastewater collected from the wastewater treatment plants during the community sporting events instead of stadium outlet; therefore, the reported elevated levels of drug consumption were not necessarily only from the game attendees.

In this study, 36 illicit and prescribed psychoactive drugs as well as 40 New Psychoactive Substances (NPS, based on frequent forensic identifications of NPS in the U.S. (NDEWS, 2019)) including 15 synthetic opioids, 11 synthetic cannabinoids, 10 synthetic cathinones, 2 piperazines, one indole, and one amphetamine derivative were determined in raw wastewater discharge collected during a high school basketball and a college basketball game in Kentucky. The target drugs include ten illicit drugs (cocaine, methamphetamine, amphetamine, heroin, morphine, methadone, MDMA, 3,4-methylenedioxyethylamphetamine, 3,4methylenedioxyamphetamine, and ${ }^{9} \Delta$-tetrahydrocannabinol [THC]); nineteen psychoactive drugs (methylphenidate, codeine, fentanyl, oxycodone, hydrocodone, hydromorphone, buprenorphine, quetiapine, aripiprazole, lorazepam, alprazolam, diazepam, oxazepam, temazepam, carbamazepine, sertraline, fluoxetine, venlafaxine, and citalopram); and their select metabolites. The samples were collected at the stadium sewer outlet to ensure the discharge only from the game attendees. The number of people using the restrooms was counted to minimize the errors associated with the population of discharging wastewater. To the knowledge of authors, this is the first study quantifying the diverse group of substance uses by the basketball game attendees.

\section{Materials and methods}

\subsection{Sample collection}

Raw wastewater samples ( $500 \mathrm{~mL})$ were collected from the utility maintenance hole outside the stadium during a men's college basketball game and high school boys' basketball game in late January 2020 and early February 2020, respectively. Both games were played at the same stadium. Samples were collected at five-minute intervals from $\sim 30$ min before the game started to $30 \mathrm{~min}$ after the game ended. Two consecutive collections were combined that provided composite samples representing ten-minute periods that provided sixteen 1-L samples in a college game and fourteen 1-L samples in a high school game. All samples were collected in one-liter polypropylene bottles, stored in ice during sample collection, immediately stored at $-20^{\circ} \mathrm{C}$, and extracted within 4 days. The counted total restroom users were 2367 in the college basketball game and 985 in the high school basketball game.

\subsection{Sample preparation}

Samples were prepared following the procedures described elsewhere (Skees et al., 2018; O'Rourke and Subedi, 2020). Briefly, $100 \mathrm{~mL}$ of samples (acidified for NPS to $\mathrm{pH} \sim 2$ ) were centrifuged at $4500 \mathrm{rpm}$ for 5 min followed by vacuum filtration using $0.45 \mu \mathrm{m}$ Nylon Membrane filter paper (MilliporeSigma, St Louis, MO). Filtrates were spiked with 50 or $150 \mathrm{ng}$ of internal standards (50 or $100 \mathrm{ng}$ for NPS) for each drug and mixed well. Oasis ${ }^{\circledR}$ HLB 6 cc solid phase extraction cartridges (Oasis ${ }^{\circledR}$ MCX 6 cc cartridge for NPS) were conditioned with $3 \mathrm{~mL}$ of methanol followed by $3 \mathrm{~mL}$ of ultrapure water (aqueous formic acid, $\mathrm{pH} \sim 2$ for NPS) before extracting the wastewater samples $(\sim 1 \mathrm{~mL} / \mathrm{min}$ under ambient temperature and pressure). After extraction, cartridges were dried under vacuum for $\sim 5$ min before eluting with $4 \mathrm{~mL}$ of methanol and $3 \mathrm{~mL}$ of $5 \%$ ammonia in methanol $(5.0 \mathrm{~mL}$ of $5 \%$ ammonia in methanol for NPS). The extracts were concentrated to $\sim 500 \mu \mathrm{L}$ using a gentle flow of nitrogen under ambient temperature, transferred to amber-silanized HPLC vials, and the final volume was adjusted to 1 $\mathrm{mL}$ using methanol. One $\mu \mathrm{L}$ of all prepared samples was subjected to Ultra-performance liquid chromatography (UPLC)- tandem mass spectrometer (MS/MS) analysis.

The target drug residues were determined using the developed and validated analytical methods (Skees et al., 2018; O'Rourke and Subedi, 2020) ${ }^{2}$ using UPLC (Agilent 1290 Infinity II LC System) coupled with MS/MS (Agilent 6460 Triple Quadrupole Mass Spectrometer). A Force Biphenyl ${ }^{\circledR}$ column $(100 \mathrm{~mm} \times 2.1 \mathrm{~mm}$ i.d. $\times 1.8 \mu \mathrm{m}$ particle size $)$ and a gradient flow of HPLC-grade methanol and $0.1 \%$ aqueous solution of formic acid were utilized to chromatographically separate target analytes. Mobile phase program and MRM transitions in positive ionization mode, and relevant optimized parameters are described elsewhere (Skees et al., 2018; O'Rourke and Subedi, 2020). The calibration curves consisting of seven to ten calibration standard points yielded regression coefficients $\left(r^{2}\right) \geq 0.99$ for all analytes.

\subsection{Quality assurance and quality controls}

A method blank ( $n=2$; ultrapure water) was also prepared and analyzed along with the wastewater samples. All reported data herein are blank-corrected. A calibration check standard ran before and after every 10 samples provided $88.0 \pm 14.1 \%$ (THC) to $121 \pm 5.51 \%$ (benzoylecgonine) recovery of target drugs. A random sample that was considered for the matrix spike $(\mathrm{n}=2)$ analysis and spiked target drugs at 50 or $150 \mathrm{ng}$ provided $57.7 \pm 3.25 \%$ (carbamazepine) to $138 \pm$ $3.83 \%$ (morphine) recoveries after processed exactly same as other samples. Limit of detection (LOD) and limit of quantification (LOQ) have considered the concentration of drugs providing a signal to noise ratio of 3 and 10, respectively, in a drug spiked sample, and are provided elsewhere (Skees et al., 2018; Croft et al., 2020; O'Rourke and Subedi, 2020). 
Analytical data points detected $<$ LOQ were substituted with $1 / 2$ LOQ values when the detection frequency is $\geq 70 \%$. A non-parametric Mann-Whitney Rank Sum test was performed to evaluate the statistical significance at 5\% significance level using SigmaPlot 12.0.

\section{Results and discussion}

\subsection{Illicit and prescribed psychotic drugs}

Thirty-three illicit and prescribed psychotic drug residues (out of target 36) as well as five new psychoactive substances (out of target 40 ), were detected in wastewater discharged during college and high school basketball games (Table 1). Among stimulants, cocaine, amphetamine, and methylphenidate were quantified in all wastewater samples collected in both basketball games. The level of cocaine was significantly higher in a college game $(p<0.001)$ whereas amphetamine $(p=0.040)$ and methylphenidate ( $p=0.002$ ) were significantly higher in wastewater discharged from the high school game (Table 1; Fig. 1).

A significantly larger number of school sports fans ( 336 million in 2009/10) attend high school basketball and football games than college and professional basketball and football games ( 133 million) (Reynolds, 2011). The average age of college basketball spectators was 26.3 years (range: 21 to 55) (England and Larsen, 2014) which is most likely a higher age than the average age of high school basketball spectators assuming a similar proportion of $35+$ age group spectators in both games. A higher past-year prevalence of cocaine among the $18-25$ age group (5.8\% in 2018) than the $12-17$ age group (0.4\%) was reported by the National Survey on Drug Use and Health (SAMHSA, 2019). Similarly, non-medical use of stimulants among students is typically in the form of the formulations (Adderall ${ }^{\circledR}$ and Ritalin $® /$ methylphenidate) that are primarily prescribed for attention deficit hyperactivity disorder and narcolepsy (Miech et al., 2020; Low and Gendaszek,

Table 1

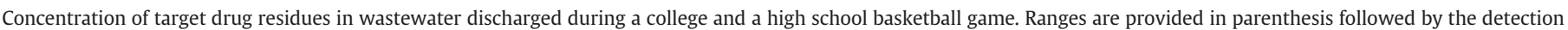
frequencies.

\begin{tabular}{|c|c|c|c|c|}
\hline \multirow[t]{2}{*}{ Analytes } & \multicolumn{2}{|l|}{ College basketball game } & \multicolumn{2}{|c|}{ High school basketball game } \\
\hline & $\begin{array}{l}\text { Median concentration } \\
(n=16 ; \mathrm{ng} / \mathrm{L})\end{array}$ & $\begin{array}{l}\text { Mass load } \pm \text { St. Dev. } \\
(\mathrm{mg} / 1000 \text { people/game) }\end{array}$ & $\begin{array}{l}\text { Median concentration } \\
(n=14 ; \mathrm{ng} / \mathrm{L})\end{array}$ & $\begin{array}{l}\text { Mass load } \pm \text { St. Dev. } \\
(\mathrm{mg} / 1000 \text { people/game })\end{array}$ \\
\hline \multicolumn{5}{|l|}{ Stimulants } \\
\hline Cocaine* & $4.07(0.72-18.5) 100 \%$ & $0.65 \pm 0.04$ & $1.22(0.50-2.29) 100 \%$ & $0.17 \pm 0.01$ \\
\hline Benzoylecgonine & $4.32(2.81-17.3) 100 \%$ & $0.75 \pm 0.03$ & $2.01(1.41-3.93) 43 \%$ & $0.14 \pm 0.02$ \\
\hline Norcocaine & $1.45(0.30-2.09) 31 \%$ & $0.05 \pm 0.005$ & $2.47(0.57-5.72) 29 \%$ & $0.09 \pm 0.02$ \\
\hline Cocaethylene & $0.48(0.36-0.58) 44 \%$ & $0.01 \pm 0.001$ & $0.46(0.34-0.58) 14 \%$ & $0.01 \pm 0.0001$ \\
\hline Amphetamine** & 343 (71.7-4790) 100\% & $116 \pm 9.63$ & 1270 (220-7050) 100\% & $296 \pm 21.8$ \\
\hline Methamphetamine & $6.35(4.42-14.3) 81 \%$ & $0.75 \pm 0.02$ & 5.50 (3.67-25.5) 64\% & $0.75 \pm 0.11$ \\
\hline Methylphenidate** & $1.75(0.45-276) 100 \%$ & $2.73 \pm 0.46$ & 19.7 (8.46-113) 100\% & $4.07 \pm 0.26$ \\
\hline \multicolumn{5}{|l|}{ Opioids/narcotics } \\
\hline Morphine & 3.23 (1.95-97.2) 94\% & $1.16 \pm 0.16$ & $2.09(7 \%)$ & 0.01 \\
\hline Methadone & $<\mathrm{LOQ}$ & na & nd & na \\
\hline EDDP & $0.67(0.44-1.03) 56 \%$ & $0.04 \pm 0.001$ & $0.53(0.20-2.21) 100 \%$ & $0.07 \pm 0.003$ \\
\hline Fentanyl & $0.13(0.11-0.22) 19 \%$ & $0.003 \pm 0.0003$ & $0.15(0.11-0.42) 21 \%$ & $0.01 \pm 0.001$ \\
\hline Oxycodone & $95.1(19.5-240) 38 \%$ & $4.11 \pm 0.54$ & 64.5 (19.5-2180 100\% & $46.9 \pm 8.16$ \\
\hline Hydrocodone ${ }^{* *}$ & 66.7 (3.59-351) 100\% & $10.3 \pm 0.61$ & 11.5 (4.94-136) 100\% & $4.03 \pm 0.51$ \\
\hline Hydromorphone* & 2.23 (1.06-6.95) 94\% & $0.34 \pm 0.02$ & 9.02 (7.77-11.6) 57\% & $0.74 \pm 0.04$ \\
\hline Buprenorphine & nd & na & $2.78(0.60-7.23) 100 \%$ & $0.30 \pm 0.02$ \\
\hline \multicolumn{5}{|l|}{ Hallucinogens } \\
\hline MDMA & nd & na & $0.84(0.25-2.18) 21 \%$ & $0.03 \pm 0.01$ \\
\hline MDEA & nd & na & $0.42(0.18-0.65) 14 \%$ & $0.01 \pm 0.002$ \\
\hline MDA & $2.53(0.17-8.40) 63 \%$ & $0.25 \pm 0.02$ & $4.64(0.05-8.35) 100 \%$ & $0.54 \pm 0.03$ \\
\hline THC & 75.0 (65.5-81.0) 19\% & $1.50 \pm 0.06$ & 57.5 (52.5-62.9) $14 \%$ & $1.13 \pm 0.31$ \\
\hline THC-COOH & 470 (71.8-1320) 31\% & $19.5 \pm 3.18$ & 473 (177-595) 57\% & $42.6 \pm 5.55$ \\
\hline THC-OH & $173(138-373) 19 \%$ & $5.10 \pm 1.03$ & 175 (101-1240) 29\% & $15.9 \pm 5.65$ \\
\hline \multicolumn{5}{|l|}{ Antischizophrenics } \\
\hline Aripiprazole & 4.23 (3.62-12.2) 69\% & $0.42 \pm 0.02$ & $2.94(7 \%)$ & 0.03 \\
\hline Quetiapine & $6.74(6.42-8.89) 100 \%$ & $0.81 \pm 0.01$ & $6.54(0.50-6.92) 100 \%$ & $0.75 \pm 0.03$ \\
\hline \multicolumn{5}{|c|}{ Sedatives/hypnotics/anxiolytics } \\
\hline Alprazolam & nd & na & $17.7(6.62-17.9) 21 \%$ & $0.41 \pm 0.09$ \\
\hline Diazepam & $<\mathrm{LOQ}$ & na & nd & na \\
\hline Oxazepam & $39.0,6 \%$ & 0.26 & nd & na \\
\hline Temazepam & 24.5 (19.4-29.7) 13\% & $0.35 \pm 0.06$ & $83.4(7 \%)$ & 1.04 \\
\hline Carbamazepine & $<\mathrm{LOQ}$ & na & 3.05 (2.87-16.8) 21\% & $0.18 \pm 0.06$ \\
\hline Gabapentin** & 22,800 (457-31,700) 100\% & $5050 \pm 1320$ & 768 (373-80,800) 100\% & $1110 \pm 190$ \\
\hline \multicolumn{5}{|l|}{ Antidepressants } \\
\hline Sertraline & $9.94(2.23-87.1) 100 \%$ & $2.00 \pm 0.15$ & 12.3 (8.89-27.9) $100 \%$ & $1.75 \pm 0.05$ \\
\hline Fluoxetine ${ }^{* *}$ & $16.2(8.18-175) 100 \%$ & $3.10 \pm 0.29$ & $30.0(2.29-333) 100 \%$ & $6.53 \pm 0.53$ \\
\hline Venlafaxine & 118 (15.2-2030) 100\% & $54.7 \pm 4.89$ & 119 (12.4-3060) 100\% & $80.5 \pm 9.98$ \\
\hline Citalopram & 590 (163-6540) 100\% & $165 \pm 11.9$ & $624(220-3310) 100 \%$ & $128 \pm 8.54$ \\
\hline \multicolumn{5}{|l|}{ New psychoactive substances } \\
\hline Methcathinone & $8.20(0.60-33.2) 100 \%$ & $1.15 \pm 0.08$ & $10.8(0.60-42.7) 100 \%$ & $2.03 \pm 0.14$ \\
\hline 4-Methyl Amphetamine & $23.8(16.0-32.0) 63 \%$ & $1.64 \pm 0.03$ & $25.4(14.0-34.4) 43 \%$ & $1.13 \pm 0.07$ \\
\hline $\mathrm{mCPP}$ & 39.7 (7.63-109) 63\% & $3.82 \pm 0.34$ & $15.3(4.25-83.0) 43 \%$ & $1.39 \pm 0.24$ \\
\hline 4-Methyl Pentedrone & 2.70 (1.97-3.40) $44 \%$ & $0.13 \pm 0.004$ & 4.07 (1.92-7.06) 100\% & $0.55 \pm 0.02$ \\
\hline 4-ANPP & $1.56(1.51-1.80) 31 \%$ & $0.06 \pm 0.001$ & nd & na \\
\hline
\end{tabular}

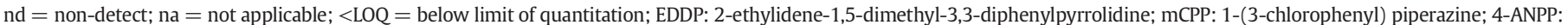
4-aminophenyl-1-phenethylpiperidine.

* Analytes that were significantly different $(p<0.001)$ in college basketball and high school basketball games using Mann-Whitney Rank Sum Test $(a$ non-parametric test).

** Analytes that were significantly different $(p<0.050)$ in college basketball and high school basketball games using Mann-Whitney Rank Sum Test $(a$ non-parametric test). 

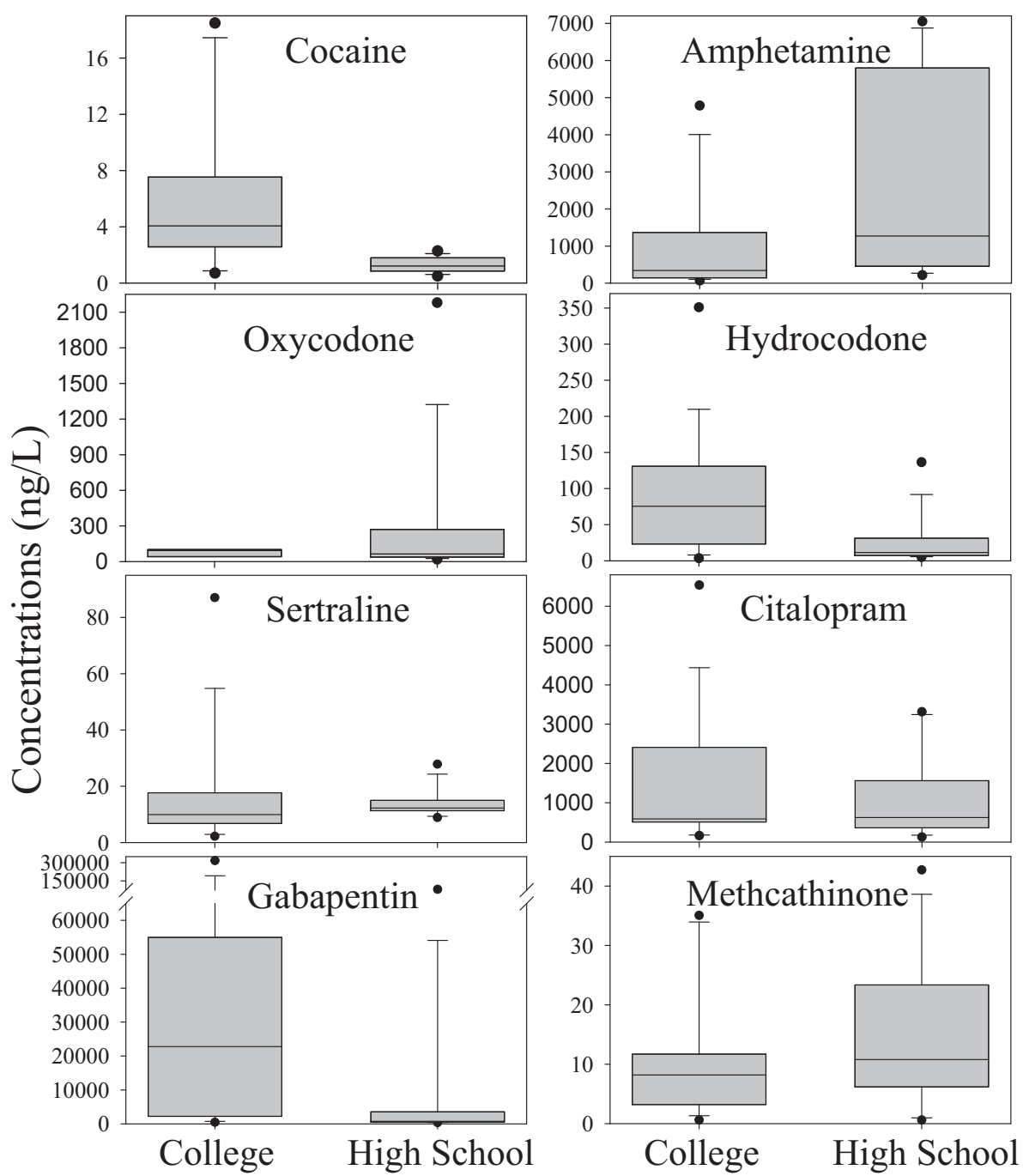

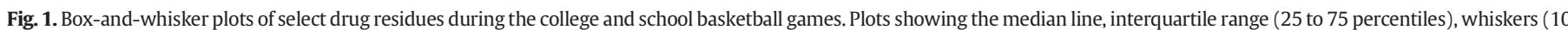
and 90 percentiles), and outliers.

2002). The annual prevalence of amphetamines among 8-12th graders was second only to marijuana (Miech et al., 2020).

The ratio of cocaine and its primary metabolite, benzoylecgonine, in wastewater is typically within a range of $0.27-0.75$ based on their human excretion rates and the molar masses (Bijlsma et al., 2012). In this study, the ratio of cocaine and benzoylecgonine concentrations during the college basketball game was 0.98 (ten out of 16 samples ranged from 0.79 to 1.84 ); however, only one sample had $>0.75$ during the high school basketball game. It suggests that a significant amount of cocaine was directly discharged down the drain during the college basketball game.

In Kentucky, hydrocodone and gabapentin doses are the two most prescribed controlled substances in the first quarter of 2020 (KASPER, 2020). In fact, the prescription rate of opioids (primarily hydrocodone: 79.5 prescriptions/1000 people in 2018) in Kentucky was the highest in the country only after Alabama, Arkansas, and Tennessee (CDC, 2019) and the prescription rate of gabapentin in Kentucky (45 prescriptions/1000 people in 2016) were the highest in the country (Pauly et al., 2020). More interestingly, the prevalence of opioids was significantly higher among individuals who were prescribed gabapentin (Pauly et al., 2020). In this study, hydrocodone and gabapentin were detected in all wastewater samples in both games. The wastewater concentrations of hydrocodone (3.59-351 ng/L) and gabapentin (457-31,700 $\mathrm{ng} / \mathrm{L}$ ) were significantly higher ( $p=0.004$ and 0.006 , respectively) during the college basketball game than in the high school basketball game. Unlike hydrocodone and gabapentin, the hydromorphone concentrations were significantly higher $(p<0.001)$ in a high school game.

Venlafaxine, sertraline, fluoxetine, and citalopram are among the top 50 most prescribed drugs in the U.S., and the latter three are the top three prescribed selective serotonin reuptake inhibitors in the U.S. (Fuentes et al., 2018). All four target antidepressants were found in all samples in both games, and fluoxetine was significantly higher ( $p=0.029$ ) in the high school game than in a college basketball game (Table 1 ).

\subsection{New psychoactive substances}

NPSs have been introduced to mimic the effects of commonly used prescribed and illicit recreational drugs. More than 670 NPS have been recorded by the European Monitoring Centre for Drugs and Drug Addiction (Celma et al., 2019). National Drug Early Warning System reported 3338 counts of synthetic opioid, 430 counts of synthetic cannabinoid, and 54 counts of synthetic cathinone seizures in Kentucky in 2018 (NDEWS, 2018). In this study, methcathinone was detected in all wastewater samples collected in both games at 0.60-42.7 ng/L (Table 1, Fig. 1). To the author's knowledge, there are no other studies that quantified NPS in wastewater during sporting events. One study quantified seven NPS (butylone, butyryl fentanyl, furanyl fentanyl, methoxetamine, 
N-ethylpentylone, pentylone, and valeryl fentanyl) during the Christmas and New Year holidays in South Australia (Merlo et al., 2011). Methcathinone was the most frequently detected NPS at the highest concentrations in untreated wastewater collected at the centralized municipal wastewater treatment plants from four southern Illinois communities (O'Rourke and Subedi, 2020). Despite the National Institute of Drug Abuse funded study - Monitoring the Future National Survey discontinued to monitor the prevalence of synthetic cathinones after 2018 owing to a relatively lower prevalence $(<0.9 \%)$ among 8th to 12th-grade school students in the U.S. (Miech et al., 2020); the detection of two synthetic cathinones (methcathinone and 4-methyl pentedrone) and other three NPSs (4-ANPP, MCPP, and 4-methylamphetamine) in wastewater indicates the prevalence of NPSs in Kentucky.

To the author's knowledge, this is the first quantitative report of 4ANPP in wastewater. DEA reported 4-ANPP as the fourth most prevalent NPS in Kentucky with 128 forensic identifications in 2018 (NDEWS, 2018). However, 4-ANPP is also a known minor metabolite of fentanyl and fentanyl analogs and is a precursor contaminant found in seized fentanyl and analogs; therefore, the reported detections of this NPS in this study may originate from the presence or consumption of the parent fentanyls (Concheiro et al., 2018).

\subsection{Mass load of drug residues}

The mass load of target drug residues within each sampling period was determined based on the quantified levels of drugs in raw wastewater samples collected during the university and high school basketball games using the following equation:

$$
\begin{aligned}
\text { Mass load }= & \text { Concentration }\left(\frac{\mathrm{ng}}{\mathrm{L}}\right) \times \text { Wastewater Volume }(\mathrm{L}) \\
& \times \frac{1 \mathrm{mg}}{1,000,000 \mathrm{ng}} \times \frac{1000}{\text { Population }}
\end{aligned}
$$

where the mass load was expressed as $\mathrm{mg} / 1000$ people/game. The tap water inflow into the stadium and the number of people using restrooms were recorded during the sampling period. The restroom users were judged to be an adult or child $(<12 \mathrm{y})$. The total tap water inflow into the stadium was found within $3 \%$ of the total wastewater flushed calculated based on the average flush volume $(6.06 \mathrm{~L} / 1.6 \mathrm{gal}$ per flush) and the total restroom users. Therefore, wastewater volume during each sampling period was calculated using the number of restroom users during each sampling period ( $10 \mathrm{~min}$ ) and the average flush volume. For the "population" in the above equation to calculate the mass load of drug residues, the restrooms users that were $>12 \mathrm{y}$ age were only used assuming the drug use among $<12$ y age is negligible. Typically, the stability factor is utilized to correct for the loss/gain of target drugs in the sewer network, during sample collection ( $24 \mathrm{~h}$ composite collection), and the time prior to sample freezing. In this study, samples were collected outside the stadium (sewer time $\sim 5 \mathrm{~min}$ ), icecooled, and stored at $-20{ }^{\circ} \mathrm{C}$ within $30 \mathrm{~min}$; therefore, the correction for the stability of drug residues in wastewater was not performed.

As anticipated the wastewater outflow was spiked at the beginning of the game, during half-time, and at the end of both games (Fig. 2). The wastewater produced during a college game $(14,340 \mathrm{~L}$ ) was $\sim 2.4$ folds higher than in a high school game. Similarly, the total restroom users during a college basketball game (2367, 39\% of the official report of game attendees) were $\sim 2.8$ folds higher than in a high school game. However, the percentage of estimated $<12$ years' age restroom users during the high school basketball game $(\sim 38 \%)$ was $\sim 2.4$ folds higher than in a college game. Estimation of the population in the target study area has been one of the major challenges in wastewater-based epidemiological estimation of drug prevalence (Croft et al., 2020; Thomas et al., 2017; Brewer et al., 2012) Despite several biomarkers such as ammoniacal nitrogen (Croft et al., 2020; Been et al., 2014) coprostanol (Daughton, 2012), and cellular data information (Thomas et al., 2017) were considered superior to the census-based population, the de facto population can still be a major source of wastewater-based epidemiological estimation of drug prevalence. In this study, the mass load calculation utilized headcount restroom users; therefore, should have no or negligible uncertainties associated with the population.

There were $296 \mathrm{mg}$ of amphetamine, $46.9 \mathrm{mg}$ of oxycodone, $217 \mathrm{mg}$ of four major antidepressants, $2.03 \mathrm{mg}$ of methcathinone, and $1110 \mathrm{mg}$ of gabapentin discharged down the drain per 1000 people during a high school basketball game (Table 1). Similarly, $116 \mathrm{mg}$ of amphetamine, $4.11 \mathrm{mg}$ of oxycodone, $225 \mathrm{mg}$ of four major antidepressants, and $5050 \mathrm{mg}$ of gabapentin were discharged down the drain per 1000 people during a college basketball game (Table 1 ). The daily consumption of drugs among game attendees could not be determined as the drug

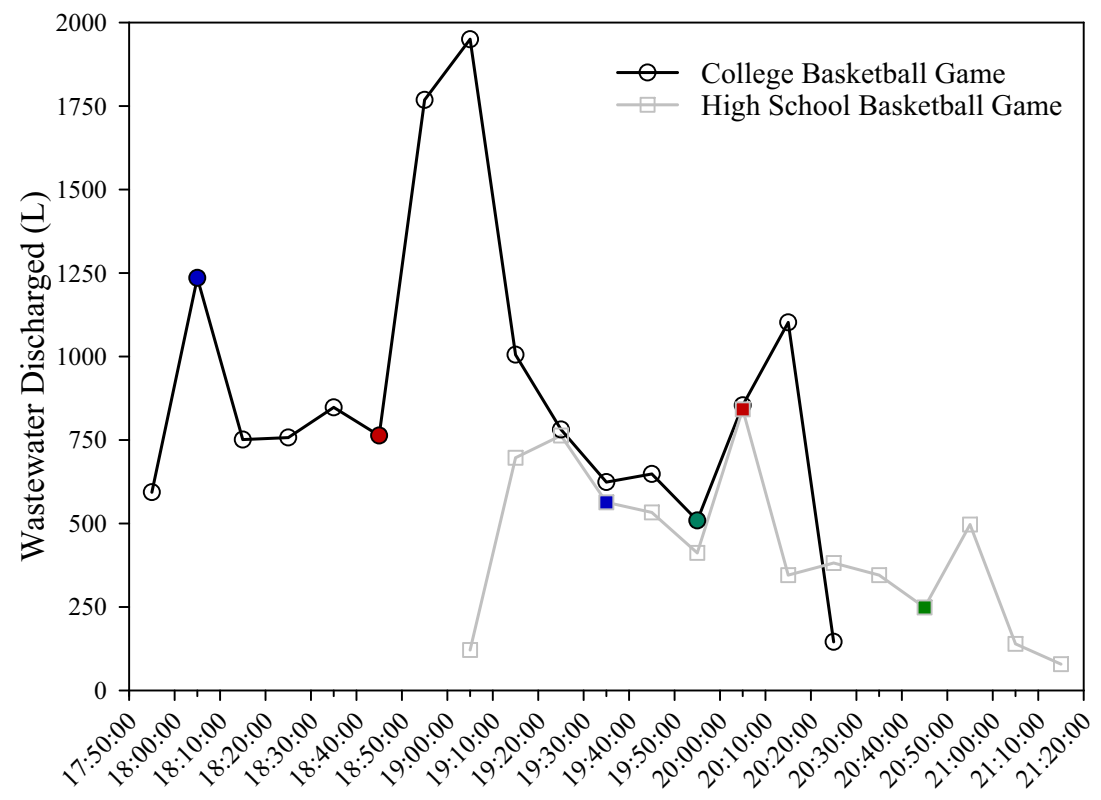

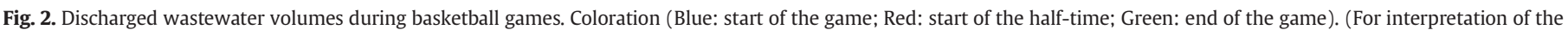
references to colour in this figure legend, the reader is referred to the web version of this article.) 
residues were only monitored for a short period ( $2.5 \mathrm{~h}$; most probably a single restroom use per person) and unaware of the time of actual drug consumption.

A significantly larger number of school sports fans ( 336 million in 2009/10) attend high school basketball and football games than college and professional basketball and football games ( 133 million) (Reynolds, 2011). Event planners, risk managers, and emergency medical service personnel can extrapolate the mass loads of drugs in wastewater in this study to evaluate the spectator behavior in relatively larger basketball gatherings. However, further studies with careful consideration of event location, age group, and the type of sporting event would be critical to establishing a nearaccurate estimation of drug consumption by the sports spectators.

\section{Conclusion}

The illicit, prescribed psychotic, and new psychoactive substances were determined in wastewater discharged from a high school and a college basketball game in Kentucky. This study found thirty-three illicit and prescribed psychotic drug residues and five new psychoactive substances for the first time at basketball games. The wastewater concentrations of amphetamine, methylphenidate, hydromorphone were significantly higher $(p \leq 0.040)$ during a high school basketball game whereas cocaine, hydrocodone, and gabapentin was significantly higher $(p \leq 0.006)$ in a college basketball game. The ratio of the concentration of cocaine to its metabolite benzoylecgonine was found that suggested a significant amount of cocaine may have directly discharged down the drain during the college basketball game. Five NPSs (methcathinone, 4-methyl pentedrone, 4-ANPP, mCPP, and 4-methylamphetamine) detected in wastewater indicate the prevalence of NPSs in Kentucky.

\section{CRediT authorship contribution statement}

Alexander B. Montgomery: Sample Collection, Analysis, and Original Draft Preparation; Catherine E. O'Rourke: Sample Collection, Analysis, and Manuscript Preparation; Bikram Subedi: Conceptualization, Sample Collection, Analysis, Manuscript Preparation, Supervision.

\section{Declaration of competing interest}

The authors declare that they have no known competing financial interests or personal relationships that could have appeared to influence the work reported in this paper.

\section{Acknowledgements}

Authors are thankful to the Jones/Ross Research Center at the Department of Chemistry, Murray State University for providing access to the UPLC-MS/MS. Authors appreciate Huichang Chae, Isaac Bowers, Katherine Veach, Cheyenne Siffel, and Houston Hampton for helping with sampling. We greatly appreciate city officials for providing access to the utility maintenance hole and assisting in sampling. This study was funded by grants from the Kentucky Biomedical Research Infrastructure Network (Grant\# NIGMS - P20GM103436).

\section{References}

Been, F., Rossi, L., Ort, C., Rudaz, S., Delémont, O., Esseiva, P., 2014. Population normalization with ammonium in wastewater-based epidemiology: application to illicit drug monitoring. Environ. Sci. Technol. 48, 8162-8169.

Bijlsma, L., Emke, E., Hernandez, F., de Voogt, P., 2012. Investigation of drugs of abuse and relevant metabolites in Dutch sewage water by liquid chromatography coupled to high-resolution mass spectrometry. Chemosphere 89, 1399-1406.

Brewer, A.J., Ort, C., Banta-Green, C.J., Berset, J.D., Field, J.A., 2012. Normalized diurnal and between-day trends in illicit and legal drug loads that account for changes in population. Environ. Sci. Technol. 46, 8305-8314.

CDC, 2019. Centers for Disease Control and Prevention. U.S. State Prescribing Rates, 2018. https://www.cdc.gov/drugoverdose/maps/rxstate2018.html. (Accessed 10 July 2020).
CDC, 2020a. Centers for Disease Control and Prevention. Drug Overdose Deaths. https:// www.cdc.gov/drugoverdose/data/statedeaths.html. Accessed on April 17 ${ }^{\text {th }}, 2020$ (accessed 2020/7/10).

CDC, 2020b. Centers for Disease Control and Prevention. Drug Overdose Mortality by State. https://www.cdc.gov/nchs/pressroom/sosmap/drug_poisoning_mortality/ drug_poisoning.htm. (Accessed 10 July 2020).

Celma, A., Sancho, J.V., Salgueiro-Gonzalez, N., Castiglioni, S., Zuccato, E., Hernandez, F. Lubertus, B., 2019. Simultaneous determination of new psychoactive substances and illicit drugs in sewage: potential of micro-liquid chromatography tandem mass spectrometry in wastewater-based epidemiology. J. Chromatogr. A 1602, 300-309.

Concheiro, M., Chesser, R., Pardi, J., Cooper, G., 2018. Postmortem toxicology of new synthetic opioids. Front. Pharmacol. 9, 1-18.

Croft, T.L., Huffines, R.A., Pathak, M., Subedi, B., 2020. Prevalence of illicit and prescribed neuropsychiatric drugs in three communities in Kentucky using wastewater-based epidemiology and Monte Carlo simulation for the estimation of associated uncertainties. J. Hazard. Mater. 384, 121-360.

Daughton, C.G., 2012. Real-time estimation of small-area populations with human biomarkers in sewage. Sci. Total Environ. 414, 6-21.

DEA, 2018. U.S. Department of Justice Drug Enforcement Administration. 2018 Nationa Drug Threat Assessment. https://www.dea.gov/sites/default/files/2018-11/DIR-03218\%202018\%20NDTA\%20final\%20low\%20resolution.pdf. (Accessed 10 July 2020).

England, B., Larsen, J.B., 2014. Noise levels among spectators at an intercollegiate sporting event. Am. J. Audiol. 23, 71-78.

Foppe, K.S., Weinberger, D., Subedi, B., 2018. Estimation of the consumption of illicit drugs during special events in two communities in Western Kentucky, USA. Sci. Total Environ. 633, 249-256.

Fuentes, A.V., Pineda, M.D., Venkata, K.C.N., 2018. Comprehension of top 200 prescribed drugs in the US as a resource for pharmacy teaching, training and practice. Pharmacy 6, 43-53.

Gerrity, D., Trenholm, R.A., Snyder, S.A., 2011. Temporal variability of pharmaceuticals and illicit drugs in wastewater and the effects of a major sporting event. Water Res. 45 5399-5411.

Gul, W., Stamper, B.J., Godfrey, M., ElSohly, M.A., 2016. LC-MS-MS method for stimulants in wastewater during football games. J. Anal. Toxicol. 40, 124-132.

Hutton, A., Ranse, J., Munn, M.B., 2018. Developing public health initiatives through understanding motivations of the audience at mass-gathering events. Prehosp. Disaster Med. 33, 191-196.

KASPER, 2020. Kentucky all schedule prescription electronic reporting. Quarterly trend report 1st quarter 2020. https://chfs.ky.gov/agencies/os/oig/dai/deppb/Documents/ KASPER_Quarterly_Trend_Report_Q1_2020.pdf. (Accessed 10 July 2020).

KODCP, 2020. Kentucky Office of Drug Control Policy. 2019 Combined Annual Report: Kentucky Office of Drug Control Policy. Kentucky Agency for Substance Abuse Policy https://odcp.ky.gov/Reports/2019\%20annual\%20report\%20final.pdf. (Accessed 10 July 2020).

Lai, F.Y., Bruno, R., Hall, W., Gartner, C., Ort, C., Kirkbride, P., Prichard, J., Thai, P.K., Carter, S. Mueller, J.F., 2013. Profiles of illicit drug use during annual key holiday and control periods in Australia: wastewater analysis in an urban, a semi-rural and a vacation area. Addiction 108, 556-565.

Low, K.G., Gendaszek, A.E., 2002. Illicit use of psychostimulants among college students: a preliminary study. Psychol. Health Med. 7, 283-287.

Merlo, L.J., Ahmedani, B.K., Barondess, B.A., Bohnert, K.M., Gold, M.S., 2011. Alcohol consumption associated with collegiate American football pre-game festivities. Drug Alcohol Depend. 116, 242-245.

Miech, R.A., Johnston, L.D., O'Malley, P.M., Bachman, J.G., Schulenburg, J.E., Patrick, M.E. 2020. Monitoring the Future National Survey Results on Drug Use, 1975-2019: Volume I, Secondary School Students. Institute for Social Research, The University of Michigan, Ann Arbor http://monitoringthefuture.org/pubs.html\#monographs. (Accessed 10 July 2020).

NCES (Ed.), 2019. National Center for Educational Statistics. Digest of Education Statistics https://nces.ed.gov/programs/digest/d18/tables/dt18_303.40.asp. (Accessed 10 July 2020).

NDEWS, 2018. National Drug Early Warning System. Drug Category by State and Year. https://ndews.umd.edu/feature/nflis-data-dashboards/. (Accessed 10 July 2020).

NDEWS, 2019. National Drug Early Warning System. Emerging Threat Report - Annua 2019. https://ndews.umd.edu/sites/ndews.umd.edu/files/DEA-Emerging-Threat-Report-2019-Annual.pdf. (Accessed 10 July 2020).

NIDA, 2014. National Institute on Drug Abuse. Principles of Adolescent Substance Use Disorder Treatment: A Research-Based Guide. https://www.drugabuse.gov/publications/ principles-adolescent-substance-use-disorder-treatment-research-based-guide/introduction. (Accessed 10 July 2020).

O'Rourke, C.E., Subedi, B., 2020. Occurrence and mass loading of synthetic opioids, synthetic cathinones, and synthetic cannabinoids in wastewater treatment plants in four U.S. communities. Environ. Sci. Technol. 54, 6661-6670.

Pauly, N.J., Delcher, C., Slavova, S., Lindahl, E., Talbert, J., Freeman, T.R., 2020. Trends in gabapentin prescribing in a commercially insured U.S. adult population, 2009-2016. J. Managed Care \& Specialty Pharm. 26, 246-252.

Reynolds, E., 2011. 510 Million Fans Attend High School Sporting Events. http://www wiaa.com/condocs/con981/high_school_today_september_2011.pdf. (Accessed 10 July 2020).

SAMHSA, 2019. Substance Abuse and Mental Health Services Administration. Key Substance Use and Mental Health Indicators in the United States: Results from the 2018 National Survey on Drug Use and Health (HHS Publication No. PEP19-5068, NSDUH Series H-54). Center for Behavioral Health Statistics and Quality, Substance Abuse and Mental Health Services Administration, Rockville, MD https://www. samhsa.gov/data/. (Accessed 10 July 2020). 
Skees, A.J., Foppe, K.S., Loganathan, B., Subedi, B., 2018. Contamination profiles, mass loadings, and sewage epidemiology of neuropsychiatric and illicit drugs in wastewater and river waters from a community in the Midwestern United States. Sci. Total Environ. 631-632, 1457-1464.

Thomas, K.V., Amador, A., Baz-Lomba, J.A., Reid, M., 2017. Use of mobile device data to better estimate dynamic population size for wastewater-based epidemiology. Environ. Sci. Technol. 51, 11363-11370.

UNODC, 2019. United Nations Office on Drug and Crime. World Drug Report 2019: 35 Million People Worldwide Suffer from Drug Use Disorders while Only 1 in 7 People Receive Treatment. https://www.unodc.org/unodc/en/press/releases/2019/June/ world-drug-report-2019 -35-million-people-worldwide-suffer-from-drug-use-disorders-while-only-1-in-7-people-receive-treatment.html. (Accessed 10 July 2020).

van Nuijs, A.L.N., Mougel, J.F., Tarcomnicu, I., Bervoets, L., Blust, R., Jorens, P.G., Neels, H., Covaci, A., 2011. Sewage epidemiology - a real-time approach to estimate the consumption of illicit drugs in Brussels, Belgium. Environ. Int. 37, 612-621.

Wolfe, J., Martinez, R., Scott, W.A., 1998. Baseball and beer: an analysis of alcohol consumption patterns among male spectators at major-league sporting events. Ann. Emergency Med. 31, 629-632. 